Discussion We conclude that adrenaline autoinjectors offer a statistically faster method for intramuscular adrenaline administration in emergency department and acute settings for paediatric patients. This is likely to offer health benefits in a time-critical emergency but as a department policy must be balanced against potentially increased costs and the frequency of administration within drug expiry periods. Intramuscular adrenaline administration in the emergency setting raises signification human factor error risks and this was reflected in the staff favour for autoinjector administration devices.

\section{P279 A RETROSPECTIVE REVIEW OF THE PAEDIATRIC ACUTE ABDOMINAL PAIN PATHWAY IN THE EMERGENCY DEPARTMENT}

Susan Keogh*, Robert Mc Carthy, Abbey Loughnan, Maybelle Wallis. Wexford General Hospital, Wexford, Ireland

\subsection{6/archdischild-2019-epa.629}

Introduction Up to $10 \%$ of childhood emergency department (ED) presentations are for abdominal pain ${ }^{1}$. High quality treatment and efficient clinical pathways can be hard to achieve due to the broad differential diagnosis ${ }^{2}$. We therefore aimed to audit this pathway to identify areas for quality improvement.

Methods We retrospectively identified 139 children presenting to ED over a three month period triaged ${ }^{3}$ as having abdominal pain. We examined the pathway and outcome of all 40 children who required admission and a random sample of 40 non-admitted patients. We analysed their triage allocation, waiting times, number of consultations, final diagnosis and definitive management.

Results

\begin{tabular}{lll} 
Abstract P279 Table 1 & & \\
\hline Characteristic & Admitted & Non-Admitted \\
\hline Triage category: & & \\
2- Very urgent & $8(20 \%)$ & $5(12.5 \%)$ \\
3- Early assessment & $28(70 \%)$ & $24(60 \%)$ \\
4- Can wait & $4(10 \%)$ & $9(22.5 \%)$ \\
5- Non urgent & 0 & $2(5 \%)$ \\
\hline
\end{tabular}

The total time spent in the ED increased with multiple consults: for a single consult the mean time was 241 minutes, compared to 240 minutes for 2 consults, 346 minutes for 3 consults 346 minutes, and 417 minutes for 4 consults.

Of breached waiting time targets, $12(30 \%)$ were caused by ED staff, $11(25 \%)$ by paediatrics, $18(45 \%)$ by surgeons, 9 $(22.5 \%)$ by extended ED stay for investigations or observation, and $6(15 \%)$ by delay in transfer to ward.

$21(52 \%)$ of patients were admitted under surgeons, however only $7(17.5 \%)$ of these had a surgical problem requiring surgical intervention. Of the admitted patients there were 8 patients triaged as category 2 (very urgent) and 50\% of these required appendicectomy. No patients triaged 4 or 5 required surgery. No child $<8$ years required surgery.

Conclusion Most children presenting to the ED with abdominal pain did not have a surgical problem. Surgery was most likely in children triaged 2 and aged 8 years and above. Time spent in ED could be reduced by avoiding multiple consults. We have therefore proposed a new pathway for the initial consult: paediatric team see $<8$ years; ED team see $>8$ years triaged category $3-5$; surgical team see $>8$ years triaged category 2 . We aim to re-audit patient waiting times, management by appropriate speciality and outcome.

\section{P280 PATIENT REFERRAL PATHWAYS IN ACCIDENT AND EMERGENCY DEPARTMENT OF AN IRISH HOSPITAL, AND ITS IMPACT ON PATIENT WAITING TIME}

${ }^{1}$ Muhammad Ghias*, ${ }^{2}$ Mathew Varghese. 'University Hospitals Leicester, Leicester, UK; ${ }^{2}$ Our Lady of Lourdes Hospital, Drogheda, Ireland

\subsection{6/archdischild-2019-epa.630}

Background Number of children attending the paediatric accident and emergency (A\&E) department has seen an increase over the years. Paediatric A\&E is primarily meant for accidents and emergencies. Paediatric patients (Excluding injuries and acutely unwell patients) are expected to be seen by general practitioner (GP) initially and get referred to A\&E if needed. Recently the number of self referring patients has seen a mount resulting in overcrowding in A\&E, which could drain out the resources including increase in waiting time.

Objectives To study patient referral pathways in Accident \& Emergency(A\&E) department and its impact on patient waiting time.

Methods All paediatric patients presenting to A\&E from 9th March 2016 to 23rd March 2016 (excluding injury and review patients) were studied. Individual clinical notes were reviewed.

Result Out of total 820 patients, 241(29\%) were studied after excluding trauma patients. Based on Paediatric Early Warning Score (PEWS) patients were divided into categories 1 to 4 with category 1 being the most unwell patients. The expected time to be seen by a doctor entails category 1 - immediately, category 2 within 10 minutes, category 3 within 1 hour and category 4 within 4 hours. Category 4 patients were considered to be non urgent referrals, expected to be managed at General Practitioner(GP). There were 140 (58\%) self referrals outnumbering 90 (37\%) GP and 11 (5\%) orthopaedic referrals. Interestingly 156 (65\%) patients were category 3 and 46 (19\%) were category 4. All category 1 patients were seen immediately. Category 2 patients faced an average waiting time of 26 minutes; this was 83 minutes in category 3 and 65 minutes in category 4 patients.

Conclusion Increased number of self referring patients particularly category 4, increased the waiting time for sick patients (category 2 and 3 ).

Encouraging non-urgent patients to be seen by the GP initially may have a beneficial effect on state resources in terms of time, manpower, waiting time and finance. This needs patient education. 